\title{
Sevilla, Febrero de 1918. El bloque de izquierdas y las elecciones de la renovación(*)
}

\section{ANGELES GONZÁLEZ FERNÁNDEZ}

El año 1917 señala el arranque de la crisis final de la monarquía, fecha clave que puso de manifiesto el divorcio existente entre el estado y la sociedad, entre el sistema político de la Restauración y las nuevas fuerzas sociales que intentaron transformar el sistema para adecuarlo a la nueva realidad española ${ }^{1}$.

La crisis de 1917 también se dejó sentir en Sevilla si bien adoptó una modalidad y un ritmo diferentes. La férrea censura impuesta por el gobierno impidió que los sevillanos tuvieran noticias sobre el movimiento de las Juntas de Defensa o sobre la Asamblea de parlamentarios ${ }^{2}$; por otro lado, la huelga general de agosto prácticamente pasó desapercibida en la ciudad ${ }^{3}$. Por todo ello, podemos afirmar que la crisis de 1917 no se manifestó plenamente en Sevilla sino a partir de 1918 y que, tal como afirmó el profesor Calero para Granada ${ }^{4}$, se prolongó durante tres años.

En el plano ideológico la crisis se manifestó en una reactivación de la lucha política que se tradujo no sólo en 'un notable incremento de la

( $\left.{ }^{*}\right)$ Esta comunicación se inscribe dentro de mis investigaciones sobre la Historia de los movimientos sociales en Sevilla (1900-1923), objeto de mi tesis doctoral, en curso de investigación.

(1) LACOMBA AVELlaN, J.A.: La crisis española de 1917. Madrid, 1970. Para Andalucía, véase RAMOS PALOMO, M.D.: La crisis de 1917 en Málaga. Málaga, 1987; PEÑA GUERRERO, M. A., LARA ROPEENAS, J. C. Y DOMINGUEZ DOMINGUEZ, R.M.: •Huelva y la crisis de 1917. Huelva en su Historia. Huelva, 1990. pp 449-503; LACOMBA AVELLAN, J. A.: •Andalucía en la crisis española de 1917-1918: el caso de Córdoba. Estudios Regionales, 14. 1984. pp 277-298; para el caso de Jaén, TUÑON DE LARA, M.: Luchas obreras y campesinas en la Andalucía del siglo XX: Jaén 1917-1920. Sevilla (1930-1932). Madrid, 1978. pp 2-121. Para Granada, CALERO AMOR, A.M.: Historia del movimiento obrero en Granada (1909-1923). Madrid, 1973.pp 80-123. La crisis de 1917 en Sevilla en, GONZALEZ FERNANDEZ, A.: Lucha Obrera en Sevilla. Conflictividad social en Sevilla, 1900-1917. Barcelona, 1988. pp 189-92

(2) AHN. Legajo 48, expediente $n^{2} 17$. Prensa, 1917

(3) GONZALEZ FERNANDEZ, A.: Lucha obrera en Sevilla p.191

(4) CÁLERO AMOR, A.M.: Historia del movimiento obrero, p.81. 
competitividad en los procesos electorales sino, sobre todo, en una creciente polarización de las fuerzas políticas en derechas e izquierdas $s^{5}$. Este proceso llevó al reagrupamiento de las izquierdas sevillanas en una alianza electoral encaminada a reformar el viciado sistema político. Sin embargo, como veremos, su fracaso a la hora de constituir un bloque compacto determinó su total incapacidad para reformar el sistema político. En este sentido, las elecciones de 1918 pusieron de manifiesto las diferencias insalvables que separaban a los distintos partidos de la izquierda extradinástica, diferencias que frustraron todo posible intento de renovación del sistema. Con la presente comunicación pretendemos determinar cuáles fueron esas diferencias y establecer, en definitiva, las causas del fracaso del Bloque de las Izquierdas en Sevilla

Los primeros síntomas de reactivación de las fuerzas de oposición al sistema se produjeron en el otoño de 1917 a raíz de la convocatoria por parte del Centro Andaluz de una Asamblea Ciudadana. El llamamiento se dirigía a todas las organizaciones no políticas con objeto de intervenir en las inminentes elecciones municipales, concebidas como el instrumento para movilizar a los sevillanos en la regeneración de la administración local ${ }^{6}$. Se trataba, pues, de una iniciativa similar a la realizada meses antes en Córdoba con el llamado *Manifiesto de la Nación ${ }^{7}$.

La convocatoria andalucista recibió una entusiasta acogida entre los radicales de Martínez Barrios ${ }^{8}$ y los socialistas. Igualmente, las organizaciones patronales sevillanas, en especial la Unión Comercial, aceptaron de inmediato la iniciativa; de hecho, esta última realizaba desde hacía algun tiempo una intensa labor fiscalizadora de la gestión municipal, como ha puesto de manifiesto Alvárez Rey9. No ocurrió lo mismo en lo que se refiere a las organizaciones obreras; las sociedades bajo influencia anarquista - aproximadamente una veintena - rechazaron en absoluto la invitación a participar en la lucha política y tan sólo las adheridas a UGT apoyaron la iniciativa.

(5) TUSELL, J.: Oligarquía y caciquismo en Andalucía (1890-1923). Barcelona, 1976. pp 551-552. La movilización de las derechas, El Correo de Andalucía. Jugar con fuego,, 112-1918; .El programa de las Izquierdas, 20-2-1918

(6) El Noticiero Sevillano, 15-9-1917.

(7) LOPEZ CALVO, M.: -La coalición regionalista republicana en las elecciones municipales de noviembre de 1917 en Córdoba.. Actas del II Congreso sobre el Andalucismo Histórico. Sevilla, 1987. p 723

(8) Martínez Barrios participó en la Asamblea no como jefe de los radicales, dado que la invitación se efectuó a las organizaciones no políticas, sino en representación de la Logia Isis y Osiris.

(9) ALVAREZ REY, L.: -Organizaciones patronales durante la Dictadura de Primo de Rivera: La Unión Comercial sevillana.. Revista de Historia Contemporánea, n² 4. Sevilla, 1986. p 170 
Las sesiones de la Asamblea se caracterizaron por el tono regeneracionista de las intervenciones que, en definitiva, no pasaron de solicitar del Ayuntamiento una clarificación de la gestión económica y de lanzar duras críticas a las prácticas caciquiles ${ }^{10}$. El proyecto inicial de formar un bloque electoral con vistas a las inminentes elecciones municipáles no salió adelante ante la falta de apoyo de los partidos políticos, en especial de Unión Republicana, que se mantuvo al margen de la iniciati$\mathrm{va}^{11} \mathrm{y}$, sobre todo, ante la evidente imposibilidad de obtener resultados satisfactorios. Así se puso de manifiesto en el comunicado en que se anunciaba a la opinión pública el retraimiento de las fuerzas reunidas en el proceso electoral:

- Dado como los partidos políticos tienen amañado el censo para falsificar la voluntad del cuerpo electoral, hemos convenido en que la Asamblea no presente candidatos porque nuestros esfuerzos hubieran resultado estériles y se hubieran estrellado ante el caciquismo: ${ }^{12}$.

A pesar del fracaso de la "Asamblea Ciudadana", la iniciativa del Centro Andaluz abrió el camino para la formación de un bloque de las izquierdas extradinásticas en Sevilla; bloque que, por otra parte, respondía a la alianza concertada a nivel nacional entre republicanos, reformistas y socialistas en el otoño de 1917 con objeto de conseguir una mayor eficacia en la labor de oposición al régimen ${ }^{13}$.

La convocatoria de elecciones generales para el mes de febrero de 1918 suscitó en Sevilla, al igual que en el resto del país, una intensa movilización en amplios sectores sociales al extenderse la convicción de que las Cortes resultantes tendrían un carácter constituyente ${ }^{14}$. Al mismo tiempo, aceleró los trabajos preparatorios para la formación del Bloque de las Izquierdas en la provincia. En este sentido, los radicales de Martínez Barrios fueron los primeros en reaccionar y, a comienzos de diciembre, constituyeron una Junta Provincial a la que se encomendó la tarea de definir la actitud del partido ante las elecciones generales. Simultánea-

(10) Las sesiones se celebraron los días 24 de octubre, 1, 2 y 3 de noviembre de 1917. Véase, GUICHOT Y SIERRA, A.: -La Asamblea Ciudadana para tratar de la transformación municipal. Sevilla. Reformas. Arbitrios y Administración. III,1917-1918. Igualmente, LACOMBA ABELLAN, J. A.: _Regionalismo y autonomía en la Andalucía Contemporánea (1835-1936). Granada, 1988. p 197

(11) Montes Sierra, jefe provincial de la Unión Republicana, había acudido a la primera sesión de la Asamblea en representación del Círculo Mercantil. Posteriormente se retiró de las deliberaciones.

(12) El Liberal, 4-11-1917

(13) SUAREZ CORTINA, M.: -Republicanos y reformistas ante la crisis de la monarquía de Alfonso XIII. VV. AA. La crisis de la Restauración. España entre la Primera Guerra Mundial y la II República. Madrid, 1986. p 64

(14) El Correo de Andalucía. *Nuestra candidatura., 1-2-1918 
mente, se iniciaron los contactos con las demás fuerzas de la izquierda para formar una coalición electoral, incluida Unión Republicana de José Montes Sierra, a pesar del rechazo que sentían no pocos radicales hacia el que consideraban autor principal del declive del republicanismo en la provincia ${ }^{15}$.

Los socialistas, por su parte, secundaron rápidamente la idea de una coalición electoral. No obstante, no todos los militantes eran partidarios de la alianza con partidos burgueses; de hecho, como podremos comprobar, la directiva se hallaba dividida entre aquellos que se mostraron decididos a integrarse en el Bloque y aquellos otros que secundaron el pacto sólo por disciplina a las directrices emanadas del Comité Nacional del partido. Sea como fuere, la agrupación designó tres delegados: el presidente, Fernando Ramírez, y dos miembros de la directiva, Santiago Rodríguez Cardenal y Alfonso Mejías, para que asumieran su representación en las negociaciones iniciadas con el partido radical, que culminaron a principios de enero con un llamamiento a las fuerzas extradinásticas para la constitución del Bloque de las Izquierdas en Sevilla ${ }^{16}$.

La asamblea se celebró en la sede de la Tertulia Republicana y a ella asistieron Martínez Barrios, en representación de los radicales; Rodríguez Cardenal, delegado por la Casa del Pueblo de Sevilla; García Pedregal y Muñoz San Román, por los reformistas; Domínguez Barbero y García de la Mata, por la Tertulia Republicana; por último, como representantes de Unión Repúblicana acudieron Díaz Rosales y Vaquero Díaz. Este último fue elegido presidente del Bloque aunque, en realidad, fue Martínez Barrios la cabeza rectora de la coalición. En lo que se refiere a los andalucistas, a diferencia de lo ocurrido en Córdoba, donde el centro Andaluz actuó como fuerza aglutinante de las fuerzas antidinásticas ${ }^{17}$, los sevillanos renunciaron a formar parte del Bloque y, desalentados por los nulos resultados de la Asamblea Ciudadana y en ausencia de Blas Infante, reafirmaron públicamente su línea apartidista y neutral ${ }^{18}$ :

(15) según el sentir de la mayoría de los republicanos ha tenido buena parte de culpa de que las fuerzas antidinásticas de Sevilla perdieran la gran influencia que en otro tiempo llegaron a tener. El Noticiero Sevillano, 4-1-1918.

(16) Los contactos entre radicales y socialistas eran anteriores a estos trabajos preparatorios del Comité Radical como lo demuestra el hecho de que en el mismo mes de diciembre, radicales y socialistas realizaron mitines conjuntos en los distritos rurales de Morón y Ecija.

(17) LOPEZ CALVO, M.: opus cit., p 725. Para la actuación de los regionalistas en Córdoba en la coyuntura 1918-1920, véase BARRAGAN MORIANA, A.: Conflictividad social y desarticulación política en la provincia de Córdoba 1918-1920. Córdoba, 1989, pp 237245 y $275-289$.

(18) Sobre el apartidismo de Blas Infante y los andalucistas, véase LACOMBA ABELLAN, J.A.: El partidismo político en la teoría y la praxis de Blas Infante. VV. AA.: Aproximación sqciológica al andalucismo histórico. Córdoba, 1990. pp 159-174 
'Para el regionalismo andaluz, que se halla en periodo de organización, existen tres cosas intangibles: la cuestión religiosa, las formas de gobierno y la lucha internacional. Ninguno que sea regionalista puro puede defender en público, de palabra o en sus escritos nada que tienda a dividir a los españoles en dos grupos por estos conceptos.19.

En es€ mismo manifiesto los militantes anunciaron la incapacidad del Bloque de las Izquierdas para purificar el viciado sistema político ante la extensión y arraigo de las prácticas caciquiles en la provincia, hecho este que reafirmaba, en su opinión, la conveniencia de la abstención en la lucha electoral ${ }^{20}$. Esta decisión, sin embargo, no fue óbice, para que Blas Infante - tras renunciar a su candidatura por el distrito malagueno de Gaucín -interviniera activamente en la campaña electoral del Bloque en la provincia, concretamente en la efectuada por Muñoz San Román en el distrito de Morón.

Una vez constituida la alianza de las Izquierdas, la Junta local - de acuerdo con las directrices emanadas desde Madrid- decidió presentar una candidatura cerrada por la circunscripción de Sevilla. Inicialmente se reservó uno de los puestos a Saborit, miembro del comité de la huelga general de agosto de 1917. Con objeto de nombrar a los otros dos candidatos se nombró una comisión formada por el radical Domínguez Barbero, Muñoz San Román - jefe de los reformistas - y el socialista Ramírez, encargada de iniciar conversaciones con destacadas personalidades de la ciudad para su proclamación como candidatos por el Bloque. En cuanto a los distritos rurales, las candidaturas se distribuyeron de la siguiente manera: Martínez Barrios fue proclamado candidato por Marchena; Muñoz San Román por el distrito de Morón; Manuel Barrio por Ecija, y el socialista Eladio F. Egocheaga por Utrera ${ }^{21}$.

La facilidad con que se confeccionó la candidatura en estos distritos no se hizo extensiva a la capital, donde la comisión tripartita encargada de contactar con los posibles candidatos tropezó con la reiterada negativa de las personalidades consultadas con este objetivo. Así, D. Alejandro Guichot, viejo militante del republicanismo federal y con gran predicamento entre la clase trabajadora, alegó su desengaño de la política para

(19) La Palabra, 9-1-1918

(20) - El partido regionalista no presentará candidatos en las próximas elecciones de Sevilla porque en esta provincia, antes que renovación hace falta... un partido. El Regionalista,
30-1-1918.

(21) Egocheaga aceptó su designación aunque anunció que no haría campaña en el distrito al no tener posibilidades de éxito. Por el contrario, intervino activamente en la campaña electoral del republicano J. Barriobero en el distrito de Valverde del Camino, en la provincia de Huelva. Igualmente, participó en algunos actos electorales en el distrito de Morón. 
rechazar el ofrecimiento, aunque probablemente influyó en mayor medida su enemistad política hacia Martínez Barrios ${ }^{22}$. Igualmente rehusó el ofrecimiento el Dr. Salvat, catedrático de medicina de reconocido prestigio. Por su parte, el jefe de Unión Repúblicana, José Montes Sierra, antes incluso de que fuera visitado por la comisión, anunció su oposición a la candidatura cerrada y renunció a presentarse como candidato, ni siquiera en calidad de republicano independiente. Por último, el reformista Adolfo Lama, que esperaba la aprobación de su candidatura por Melquiades Alvárez, optó por negar su concurso ante las sucesivas negativas de los restantes consultados. De este modo, todas las combinaciones ensayadas (Guichot-Montes Sierra-Saborit; Salvat- Lama-Saborit) fracasaron una tras otra, y así lo reconoció la Junta Provincial de las Izquierdas en una nota oficiosa publicada el 20 de enero en estos términos:

-El criterio que acerca de los deberes de ciudadanía y que la responsabilidad que a todos los hombres políticos les corresponde en este momento solemne de la vida de España, lleva a esta Junta a la pública declaración, sin habilidades tortuosas, de que no ha tenido el éxito que apetecía y merecía su propósito de formar la candidatura cerrada del Bloque. La Junta ha dirigido a ilustres personalidades de ideas liberales compeliéndolas a que integrasen esa candidatura en aras de los altos intereses que hoy se ventilan y de las ansiadas aspiraciones de Sevilla (...) Dificultades de diversa índole han originado la no aceptación de los señores a los que tuvimos el honor de requerir. Hasta ahora, pues, no hay candidatura. ${ }^{23}$

En estas circunstancias, la Junta recurrió al Comité Nacional del Bloque en Madrid - integrado por A. Lerroux, P. Iglesias y M. Alvarez - a fin de que éste propusiera una solución al conflicto planteado. A estas alturas, era evidente para todos que la única posibilidad de triunfo radicaba en la presentación de Montes Sierra como candidato. Consciente de ello, el Comité Nacional propuso la constitución de una candidatura por las minorías que estaría formada por Montes Sierra y Saborit. No obstante, esta nueva tentativa fracasó ante la reiterada negativa de Montes Sierra a figurar junto con otro representante por las izquierdas; de hecho, para forzar aún más la situación, anunció días más tarde șu retirada del partido

(22) La enemistad de Guichot hacia Martínez Barrio se remontaba a 1910 cuando los radicales, encabezados por este último, desembarcaron en la Casa del Pueblo de Sevilla - de la que Guichot había sido uno de los fundadores - desvirtuando su objetivos sociales y convirtiéndola en plataforma de propaganda y fuente de financiación del partido radical, lo que acabó por arruinar a la Casa del Pueblo poco tiempo después. Sobre la negativa de Guichot a participar en las elecciones, véase: JIMENEZ BENITEZ, J.R.: La sociología andalucista de Alejandro Guichot. Sevilla, 1990. pp 394-395

(23) El Noticiero Sevillano, 4-1-1918 
republicano en protesta por la decisión del Bloque de ir en candidatura cerrada $^{24}$. No quedaba otra alternativa, pues, que proclamar la candidatura unipersonal de Montes Sierra, aprobada una vez que el Comité Nacional acordó dar una amplia autonomía a la Junta provincial en este punto ${ }^{25}$. Por su parte, Montes Sierra aceptó la proclamación pero anunció que no participaría en la campaña electoral e incluso afirmó su total desinterés hacia las elecciones ${ }^{26}$.

La aprobación de esta candidatura fue, sin embargo, el detonante que dinamitó el bloque de las izquierdas en Sevilla. En efecto, para los socialistas sevillanos la candidatura unipersonal de Montes Sierra, un hombre estrechamente vinculado a los círculos empresariales de la ciudad y diputado a Cortes por el encasillado en varias ocasiones ${ }^{27}$, era del todo punto inaceptable, y especialmente tras conocerse que el partido liberal le había ofrecido su apoyo para luchar contra los conservadores. Ambos hechos suponían la aceptación de las prácticas políticas vigentes $y$, por tanto, la integración de las izquierdas extradinásticas en el sistema que se pretendía purificar. En esta tesitura, la agrupación acordó anunciar su separaración del Bloque en una carta abierta en la que se puso de manifiesto el recelo con que algunos militantes lo habían acogido:

-Considerando que es consustancial con nuestras ideas la pureza en los procedimientos y que si bien desde un principio hízose solidaria de la gestión de sus representantes en el Bloque de las Izquierdas en tanto hubo de mantenerse el criterio de nuestro partido en lo que respecta a la candidatura cerrada por la circunscripción.

Los socialistas, además, denunciaron la derechización del bloque y su complicidad con las prácticas caciquiles, con *esa política de compadrazgo que con desdén de los más elementales principios de la ciudadanía es el oprobio y la ruina del pueblo y la nación. Una complicidad que,

(24) -No estando conforme con el acuerdo adoptado por la Junta del Bloque de las Izquierdas, me separo del partido republicano de esta localidad, en el que milito desde hace 40 años. El Noticiero Sevillano, 21-1-1918.

(25) Telegrama dirigido desde Sevilla al Comité Nacional: .Sometemos consideración Junta central izquierdas asunto candidatura Sevilla. Imposible formar candidatura minorías, hay representante que opina procede proclamar candidatura unipersonal. No logramos llegar acuerdo, pero estamos dispuestos acatar decisión comité central, quien mirando como nacional, si la hubiera, imposible apreciar desde aquí, resolverá libremente. Solicitamos rápida respuesta por la Junta del Bloque, Juan Vaquero. La respuesta al anterior fue el siguiente telegrama: .12 mañana conferencié $\mathrm{M}$. noche Casa Pueblo deliberamos los tres. Comité Ejecutivo encargome comunicarle aprobará sostendrá acuerdo tome ese organismo, sea cual fuere, sobre elecciones circunscripción. Saludos, Lerroux: El Noticiero Sevillano, 9-2-1918.

(26). El Noticiero Sevillano, 20-1-1918

(27) Sobre la trayectoria política de Montes Sierra, véase: VV.AA. Sevilla en el siglo XX (1868-1950), I. Sevilla, 1990. pp 157-159 
probablemente, podía enajenarles el apoyo de la clase trabajadora, cada vez más radicalizada a causa de sus difíciles condiciones de vida y, sobre todo, tras la reorganización de los anarquistas en la ciudad desde comienzos de año ${ }^{28}$. Finalmente, anunciaron la retirada de los representantes socialistas del bloque, aunque no descartaron una nueva alianza siempre que los partidos integrantes, asumieran como propio el principio de moralidad sobre el que se basaba el partido socialista ${ }^{29}$.

La carta aparecía con las firmas de dos miembros del Comité: Juan Gómez -a la sazón secretario accidental- y Alfonso Mejías, uno de los delegados en el bloque. Sin embargo, no había unanimidad entre los socialistas sevillanos; de hecho, esta cuestión provocó la primera escisión de la Agrupación Local. Inicialmente, la asamblea socialista había aceptado la candidatura por minorías en una reunión celebrada el 2 de febrero en la que ratificaron, además, su confianza en los tres representantes en el Bloque. Existía, no obstante, un grupo contrario a esta decisión encabezado por tres miembros de la directiva: Camilo Castillo, Juan Gómez y Manuel Alvárez, que consiguieron modificar la posición de la asamblea de forma que ésta acordó la retirada del Bloque con tan sólo seis votos en contra. El presidente de la Agrupación y representante en el Bloque, F. Ramírez, volcado esos días en la campaña electoral desarrollada en los distritos rurales ${ }^{30}$, no pudo impedir la maniobra; es más, conoció la ruptura del Bloque a través de la nota publicada en la prensa local.

A partir de este momento se produjo un enfrentamiento abierto en el seno del Comité de la agrupación que puso de manifiesto la disparidad de criterios existente en torno a la alianza con los partidos burgueses ${ }^{31}$. El triunfo del sector opuesto a este tipo de pactos derivó en el mantenimiento de la separación del Bloque y la pública reprobación de sus delegados en el mismo, cuya conducta fue notificada al Comité Nacional para que éste acordara las medidas sancionadoras que considerara oportunas. A pesar de ello, F. Ramírez prosiguió su intensa actividad en la campaña electoral del Bloque; concretamente, intervino en los mitines celebrados en Morón, El Coronil y Montellano los días 18, 19 y 20 de febrero en los que figuraba

(28) A comienzos de año los anarcosindicalistas sevillanos intensificaron sus trabajos de propaganda y reorganizacion de las sociedades obreras con vistas a la creación de una Federación Local, que fue constituida legalmente el 16 de febrero.

(29) :interin dé la verdadera sensación al pueblo de que en verdad va a la lucha sin menoscabar los fundamentos indestructibles de la moral de nuestro partido. El Liberal, 7-2-1918

(30) A finales de enero Ramírez participó en mitines del Bloque en las localidades de Carmona y Puebla de Cazalla. Regresó a Sevilla y el día 4 de febrero marchó al distrito de Morón para apoyar la campaña de Muñoz San Román.

(31) El Liberal, 9, 10,11 y 13-2-1918 
como jefe de los socialistas sevillanos. Sus intervenciones se caracterizaron por los reiterados llamamientos a la clase obrera para que acudiera a las urnas, insistiendo en la identificación entre los candidatos del Bloque y el pueblo trabajador. Así presentó, por ejemplo, al candidato de las izquierdas en el mitin efectuado en Montellano:

-Siendo Muñoz San Román hijo de obrero nadie más capacitado que él para conocer las necesidades y justas aspiraciones del proletariado. Combatió duramente - proseguía la reseña de El Liberal - el caciquismo ejercido por igual por conservadores y liberales contra el cual luchan las izquierdas que encarnan altos ideales democráticos. ${ }^{32}$

Paradojicámente, el día anterior El Noticiero Sevillano había publicado un manifiesto firmado por Gómez, Castillo y Alvárez que reiteraba la separación de los socialistas sevillanos del Bloque y denunciaba la alianza concertada entre las izquierdas no dinásticas y el partido liberal. Este acuerdo se concretó en el apoyo ofrecido por el jefe liberal, $P$. Rodríguez de la Borbolla, a Montes Sierra en la circunscripción y a la candidatura de Martínez Barrios en el distrito de Marchena contra el candidato conservador, el Marqués de Torrenueva. Transcribimos a continuación este texto por su carácter definitorio de la postura adoptada por la Agrupación local ante el proceso electoral:

-Compañeros: en vista de la alianza monárquico-republicana que en Sevilla y en el distrito de Marchena viene efectuándose en la contienda electoral,donde para sacar triunfante un acta de diputado se apela al contubernio de los eternos enemigos del progreso y de los trabajadores, esta agrupación se ratifica en su actitud de mantener su disconformidad en absoluto con el malogrado bloque de las Izquierdas*

El comunicado no terminaba aquí sino que a continuación expresaba una intensa desconfianza hacia los republicanos para llegar a una acción conjunta en un futuro:

-Sírvanos de dolorosa lección lo ocurrido y demostrando tener conciencia de nuestra misión, hagamos frente con virilidad y gentileza tan descaradas habilidades que en pugna y contradicción con el sentido político moderno estacionan a los pueblos retardando el momento de la redención, ${ }^{33}$.

En cuanto al proceso electoral, a pesar de la prometida limpieza en los procedimientos ${ }^{34}$, la compra de votos fue una realidad, denunciada

(32) El Liberal, 22-2-1918

(33) El Noticiero Sevillane, 21-2-1918

(34) Sobre el carácter renovador de las elecciones de 1918, MARTINEZ CUADRADO, M.: Elecciones y partidos políticos en España (1868-1931). Madrid, 1969, pp 803-4. En el caso que nos ocupa, el Boletín Oficial de la Provincia de Sevilla publicó diversas circulares instando a las autoridades a vigilar por la pureza del sufragio; en concreto los días 13, 20, 23 y 25 de febrero de 1918. 
por el propio gobernador civil que anunció su intención de salvaguardar la pureza del sufragio ${ }^{35}$. Realmente, tal como ha puesto de manifiesto el prof. Tusell, este tipo de declaraciones no constituían sino pura fachada que ocultaba la persistencia de las prácticas caciquiles sin que se produjera un cambio esencial en los procedimientos electorales seguidos ${ }^{36}$.

Las mayores irregularidades se produjeron en el distrito de Marchena, donde Martínez Barrios, apoyado por los liberales, constituía una seria amenaza para el candidato conservador; ello explica los esfuerzos de Torrenueva que obstaculizó por todos los medios la campaña electoral de su rival ${ }^{37}$. La lucha en el distrito de Morón ofreció un menor grado de prácticas caciquiles, probablemente porque el candidato del Bloque, el reformista Muñoz San Román, no suponía peligro alguno para el candidato del encasillado. La propaganda electoral de los candidatos bloquistas se fundamentaba en el alejamiento del Bloque de los partidos dinásticos y de todo el aparato político del sistema, configurándose como una fuerza política nueva creada para sanear las prácticas vigentes y combatir la corrupción y el caciquismo. Igualmente, buscaban ganarse el apoyo de las clases trabajadoras con promesas más o menos vagas sobre el mejoramiento de su nivel de vida ${ }^{38}$.

La lucha electoral fue inexistente en la circunscripción debido a la firmeza del encasillado, en el que estaba incluido el propio Montes Sierra. No es de extrañar, por tanto, el desánimo y la indiferencia con que los sevillanos vivieron la jornada electoral ${ }^{39}$. La abstención, por consiguiente, fue muy elevada y Martínez Cuadrado la estima en un $42 \%$

(35) .Se me ha denunciado que con la mayor impudicia está ofreciéndose en esta capital dinero por votos. Se me ha dicho también que se ha establecido una lonja de contratación de los mismos. Esto que parece ridículo puede ser cierto y si a estas horas hay quien confía en estos procedimietos para hacer su elección, se equivoca, puesto que estoy dispuesto a impedirlo por todos los medios.. El Noticiero Sevillano, 20-2-1918

(36) TUSELL, J.: opus cit., p 549

(37) -Marchena 22, 13,30. Amigos Torrenueva, viendo perdida elección quieren impedir celebre mitin. Parcialidad alcalde es tan notoria que tiene autorizados dos de propaganda conservadora para mañana mismo. El Noticiero Sevillano, 23-2-1918

(38) Veánse, por ejemplo, las reseñas de los mítines de Muñoz San Román en su campaña electoral. En Morón, el día 19, afirmó: -Yo no soy un político a la antigua usanza. Aspiro a una total renovación de los modos de gobernar orientados en sentido democrático. El día 21, en Montellano:-(el candidato) of reció trabajar con fe por los obreros hasta conseguir sacarlos de la esclavitud que padecen por estar desposeídos de sus justos derechos (...) Aboga por la unión de los obreros para destruir lo caduco y lo corrompido..El Noticiero Sevillano, 20 y 22-2-1918.

(38) .Sevilla ha dado una lamentable nota de indiferentismo. El Noticiero Sevillano, 25-21918; -Las elecciones de la renovación han sido una verguenza., El Liberal, 26-2-1918

(39) MARTINEZ CUADRADO, M.: Opus. cit. p 887

(40) El Liberal, 26-2-1918 
aunque El Liberal, quizás para subrayarla en exceso, denunció que en Sevilla no había votado ni la quinta parte del censo ${ }^{41}$. Tal como estaba previsto, Montes Sierra fue elegido diputado por la circunscripción con un total de 15.099 sufragios, junto con los liberales E. D'Angelo y M. Clavijo, el conde de Colombí,conservador, y el candidato de la Liga Católica, M. Rojas Marcos ${ }^{42}$.

En los distritos rurales, el Bloque de las Izquierdas tampoco obtuvo éxito a pesar de las esperanzas depositadas, especialmente en el de Marchena; en este último y a pesar del apoyo liberal, Martínez Barrios, con 2.227 votos, fue superado por el candidato conservador que obtuvo el acta con 3.195 votos. La votación fue especialmente reñida en la localidad de Marchena, donde la diferencia entre ambos candidatos fue de tan sólo 84 sufragios. En el distrito de Morón, el candidato del Bloque obtuvo un tercer puesto, con 359 votos y, por tanto, no obtuvo escaño. El mayor porcentaje de votos lo obtuvo en las localidades de Morón y Puebla de Cazalla ( 40 y $34 \%$ del total de votos respectivamente), precisamente donde las agrupaciones socialistas locales tenían una mayor fuer$z a$, lo que viene a indicarnos la independencia con que actuaban las agrupaciones socialistas de los pueblos respecto a la de Sevilla capital ${ }^{13}$.

A modo de conclusión cabe afirmar, ante todo, la imposibilidad de las izquierdas sevillanas para constituir un bloque homogéneo capaz de reformar el sistema desde dentro. En un primer momento este fracaso puede imputarse a la desorganización y debilidad de las propias fuerzas de la oposición extradinástica, como fue el caso de la Asamblea Ciudadana. Posteriormente, la coalición de las izquierdas fracasó no sólo por la debilidad de sus componentes sino, sobre todo, por la negativa de esos "hombres nuevos" a mezclarse en las prácticas viciadas del sistema aunque fuera para purificarlo. Esta negativa llevó a recurrir necesariamente a los viejos políticos integrados en el mismo régimen que se pretendía reformar, una decisión que supuso la quiebra definitiva del Bloque. Por último, la connivencia entre radicales y borbollistas, siempre desmentida

(41) Los resultados electorales en Boletín Oficial de la Provincia de Sevilla, nª 49 Y 50. 26 y 27-2-1918

(42) En otras localidades sevillanas diversos dirigentes del PSOE obtuvieron un pequeño porcentaje de votos. Así ocurrió en Peñaflor donde Saborit obtuvo 87 votos; Guillena (Besteiro, nueve votos, y Largo Caballero, nueve votos); Las Cabezas de San Juan (Egocheaga, tres votos); Lora del Río (Besteiro, un voto). Boletín Oficial de la Provincia de Sevilla, $n^{\circ} 49,26-2-1918$.

(43) Efectivamente, en las elecciones generales de junio de 1919, los socialistas de la capital se negaron a coaligarse con los radicales y junto con andalucistas y republicanos federales formaron una candidatura cerrada, denominada .Democracia Andaluza., que detrajo numerosos votos a los radicales en la circunscripción. 
por los primeros, no sólo frustró las esperanzas puestas por las fuerzas extradinásticas en las llamadas "elecciones de la renovación* sino que, además, imposibilitó una nueva coalición de las izquierdas en el futuro. Por otro lado, el fracaso determinó no sólo la rápida desaparición de la Alianza de las Izquierdas en Sevilla, sino que también tuvo serias consecuencias para sus componentes. En primer lugar, los republicanos perdieron el escaño conseguido en Sevilla tras la muerte de Montes Sierra el 2 de mayo de ese mismo año, un hecho que no vino sino a agravar la crisis interna del republicanismo sevillano a lo largo de 1918.

En segundo lugar, la escisión en el seno del Comité de la Agrupación socialista local finalizó con la expulsión de Ramírez, Mejías y Cardenal y la constitución de una segunda agrupación socialista en la capital. A partir de esta fecha advertimos, además, una progresiva pérdida de influencia de los socialistas entre las organizaciones obreras sevillanas. En el terreno de la acción política, los socialistas sevillanos vivieron como una traición la alianza entre los radicales y el partido liberal y, en consecuencia, negaron su apoyo a las fuerzas de Martínez Barrios en ulteriores elecciones, imposibilitando en buena parte el triunfo radical en $1919^{44}$.

Por último, también el partido reformista experimentó una grave crisis que culminó en el mes de diciembre con la dimisión irrevocable de Muñoz San Román y de todo su equipo directivo.

Las disensiones tanto en el seno de cada uno de los partidos integrantes como de éstos entre sí-especialmente entre socialistas y radicalesimpediría, en suma que las izquierdas antidinásticas sevillanas pudieran tener éxito en la tarea de transformar el sistema político. Por el contrario, a partir de las elecciones de 1918, las izquierdas en Sevilla se agruparon en dos bloques antagónicos: radicales y Unión Republicana, con el apoyo de la facción socialista disidente; de otro, socialistas, federales y regionalistas. Ambos bloques entablaron una dura competencia por controlar el mismo espacio social en el periodo inmediatamente siguiente. Por consiguiente, la desarticulación del sistema político en la ciudad de Sevilla no sólo afectó a los partidos dinásticos sino que, como una grangena, se había extendido también a las fuerzas políticas llamadas a renovarlo. 